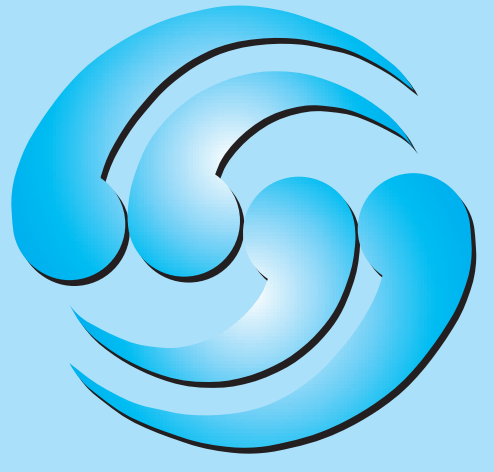

Jonathan Belsey MB BS Independent Researcher in Evidence Based Medicine
For further titles in the series, visit: wWw.whatisseries.co.uk

\section{What is evidence-based medicine?}

- The primary purpose of the NHS is '... to secure through the resources available the greatest possible improvement to the physical and mental health of the nation'. ${ }^{1}$ To achieve this, decisions about the delivery and provision of healthcare are increasingly being driven by evidence of clinical and cost-effectiveness as well as systematic assessment of actual health outcomes.

Evidence-based medicine (EBM) is the process of systematically reviewing, appraising and using clinical research findings to aid the delivery of optimum clinical care to patients. ${ }^{2}$

Increasingly, purchasers are looking to the strength and weight of scientific evidence on clinical practice and costeffectiveness when allocating resources. They are using this information to encourage healthcare professionals and NHS trusts to use treatments that have been proven to be both clinically and cost-effective, while disinvesting from practice that does not meet these objectives.

EBM forms part of the multifaceted process of assuring clinical effectiveness, the main elements of which are:

Production of evidence through research and scientific review

Production and dissemination of evidence-based clinical guidelines

Implementation of evidence-based, cost-effective practice through education and management of change

$\checkmark$ Evaluation of compliance with agreed practice guidance through clinical audit and outcomes-focused incentives. 


\section{What is evidence-based medicine?}

\section{The history of EBM}

Although the formal assessment of medical interventions using controlled trials was already becoming established in the 1940s, ${ }^{3,4}$ it was not until 1972 that Professor Archie Cochrane, director of the Medical Research Council Epidemiology Research Unit in Cardiff, expressed what later came to be known as evidence-based medicine (EBM) in his book Effectiveness and Efficiency: Random Reflections on Health Services. ${ }^{5}$ These concepts were developed into a practical methodology by groups working at Duke University in North Carolina (David Eddy) and McMaster University in Toronto (Gordon Guyatt and David Sackett) in the late 1980s and early 1990s. ${ }^{6-8}$

In 1992, the UK government funded the establishment of the Cochrane Centre in Oxford under Iain Chalmers, with the objective to facilitate the preparation of systematic reviews of randomised controlled trials of healthcare. The following year it expanded into an international collaboration of centres, of which there are now thirteen, whose role is to co-ordinate the activities of 11,500 researchers. The establishment of the Cochrane Collaboration should be considered as one of the critical factors in spreading the concept of EBM worldwide.

\section{The impact of EBM}

The basic principle of EBM - that we should treat where there is evidence of benefit and not treat where there is evidence of no benefit (or harm) - is of relevance at all levels of the NHS.

- Strategically: Bodies such as the National Institute for Health and Clinical Excellence (NICE), the Scottish Medicines Consortium and the All Wales Medicines Strategy Group use the principles of EBM, coupled with health economic analysis, in directly commissioned health technology assessments (HTAs) that inform guidance as to which treatments should be available within the NHS (see What is health technology assessment? ${ }^{9}$ for further discussion of HTAs).

- Tactically: Primary care organisations and hospital trusts formulate and implement formularies, care pathways and guidelines based on HTAs and other assessments issued by EBM-focused organisations.

- Individually: An understanding of the evidence base allows the clinician to tailor treatment to the circumstances and risk-benefit profile of the individual patient.

\section{The logic behind EBM}

To make EBM more acceptable to clinicians and to encourage its use, it is best to turn a specified problem into answerable questions by examining:

- The person or population in question

- The intervention given

- The comparison (if appropriate)

- The outcomes considered.

Next, it is necessary to refine the problem into explicit questions and then check to see whether the evidence exists. But where can we find the information to help us make better decisions?

Common sources include:

- Personal experience - for example, a bad drug reaction

- Reasoning and intuition

- Colleagues

\section{- Published evidence.}

It is only by educating healthcare professionals and making them aware of the strength of published evidence in contrast to more traditional - and less rigorous - sources of information, that the use of ineffective, costly or potentially hazardous interventions can be reduced.

\section{Accessing information}

There are many sources of information to inform clinical practice. The following website - Netting the Evidence - includes a 
comprehensive listing of internet resources for the clinician, in addition to a virtual library and tools to assist with critical appraisal and evidence implementation: www.shef.ac.uk/scharr/ir/netting

Probably the most valuable single access point is The Cochrane Library. This is accessible free of charge from any UK-based computer at: www.thecochranelibrary.com

The Cochrane Library contains high-quality, independent evidence to inform healthcare decision-making. It includes the databases shown in Box 1, all of which can be searched simultaneously from a single user interface.

\section{Analysing information}

In using the evidence it is necessary to:

- Search for and locate it

- Appraise it

Interpret it in context
Implement it

Store and retrieve it

Ensure it is updated

- Communicate it.

Every clinician strives to provide the best possible care for patients. However, given the multitude of research information available, it is not always possible to keep abreast of current developments or to translate them into clinical practice. One must also rely on published papers, which are not always tailored to meet the clinician's needs.

\section{Levels of evidence}

Evidence is presented in many forms, and it is important to understand the basis on which it is stated. The value of evidence can be ranked according to its potential for bias. Box 2 shows the classification used by the Scottish Intercollegiate Guidelines Network when

\section{Box 1. Databases included in The Cochrane Library}

The Cochrane Database of Systematic Reviews

Full-text systematic reviews and meta-analyses carried out to a common protocol and quality standard by Cochrane Collaboration researchers throughout the world. There are currently 3,625 completed reviews on the database (November 2008), with a further 1,921 protocols for works in process.

\section{The Database of Abstracts of Reviews of Effects (DARE)}

This database contains 9,025 quality-appraised abstracts of systematic reviews carried out by other researchers. Protocols and quality standards may vary but this provides a useful starting point if no appropriate Cochrane review has been carried out.

\section{The Cochrane Central Register of Controlled Trials}

All Cochrane reviews start with a comprehensive review of the literature. This database provides abstracts of all controlled studies identified by the research groups, as well as further results trawled from electronic databases. There are currently around 550,000 studies included in the register.

\section{The Health Technology Assessment Database}

Produced by the Centre for Reviews and Dissemination (CRD) at York University, this database brings together details of 7,528 health technology assessments from around the world. These reviews tend to focus on efficient use of healthcare resources and often include epidemiological and economic assessments.

\section{The NHS Economic Evaluation Database}

This also originates from the CRD and focuses purely on those reviews that evaluate the economics of healthcare interventions. It currently contains details on 24,451 such appraisals. 


\section{Box 2. SIGN classification for grading evidence ${ }^{10}$}

1++ High-quality meta-analyses, systematic reviews of RCTs, or RCTs with a very low risk of bias

1+ Well-conducted meta-analyses, systematic reviews, or RCTs with a low risk of bias

1- Meta-analyses, systematic reviews, or RCTs with a high risk of bias

$2++$ High-quality systematic reviews of case-control or cohort studies High-quality case-control or cohort studies with a very low risk of confounding or bias and a high probability that the relationship is causal

2+ Well-conducted case-control or cohort studies with a low risk of confounding or bias and a moderate probability that the relationship is causal

2- Case-control or cohort studies with a high risk of confounding or bias and a significant risk that the relationship is not causal

3 Non-analytic studies; for example, case reports, case series

4 Expert opinion

RCT: randomised controlled trial; SIGN: Scottish Intercollegiate Guidelines Network

grading evidence for its clinical guidelines. ${ }^{10}$ (See What is a systematic review? ${ }^{11}$ for further discussion.)

Although classification of this type provides a useful focus when reading clinical trial data, it is important to recognise that accurate grading requires a clear understanding of what predisposes a study to bias (Table 1). ${ }^{12}$ This is the process of critical appraisal.

\section{Critical appraisal}

For any clinician, the real key to assessing the usefulness of a clinical study and interpreting the results to an area of work is through the process of critical appraisal. This is a method of assessing and interpreting the evidence by systematically considering its validity, results and relevance to the area of work considered.

The Cochrane Collaboration, which coordinates an international network of researchers involved in systematic review, has evolved a generic approach to appraising a clinical trial, allowing the reader to make an objective assessment of study quality and potential for bias. Table 1 shows the issues assessed when appraising a randomised controlled trial (RCT). More detail and detailed examples are available on the Cochrane website. ${ }^{12}$

\section{Systematic review and meta-analysis}

Sometimes an RCT may fail to give a clear result, or results from multiple studies may yield different estimates of treatment effect. However, by identifying all published information in a given clinical area (systematic review) and pooling the results in a statistically valid fashion (metaanalysis) it is possible to arrive at a more precise estimate of treatment effect (see What is a systematic review ${ }^{11}$ and What is metaanalysis $?^{13}$ for a more detailed discussion).

This approach is very attractive, as it allows all evidence in the field of interest to be taken into account. However, the danger exists that a poorly executed systematic review and metaanalysis may give deceptive results. It is therefore important to critically appraise the paper in just the same way as one would an RCT. The following are critical issues to be aware of. ${ }^{14,15}$

- There should be a focused clinical question agreed prior to examination of the literature.

- Search strategies should include multiple sources, to reduce the risk of publication bias, and should not be subject to artificial limitations (for example, English language only).

Each individual study needs to be quality appraised, to limit the chance of biased 
Table 1. The Cochrane Collaboration's tool for assessing risk of bias ${ }^{12}$

\begin{tabular}{|c|c|c|}
\hline Domain & Description & $\begin{array}{l}\text { Review authors' } \\
\text { judgement }\end{array}$ \\
\hline $\begin{array}{l}\text { Sequence } \\
\text { generation }\end{array}$ & $\begin{array}{l}\text { Describe the method used to generate the allocation sequence in } \\
\text { sufficient detail to allow an assessment of whether it should } \\
\text { produce comparable groups }\end{array}$ & $\begin{array}{l}\text { Was the allocation } \\
\text { sequence adequately } \\
\text { generated? }\end{array}$ \\
\hline $\begin{array}{l}\text { Allocation } \\
\text { concealment }\end{array}$ & $\begin{array}{l}\text { Describe the method used to conceal the allocation sequence in } \\
\text { sufficient detail to determine whether intervention allocations could } \\
\text { have been foreseen in advance of, or during, enrolment }\end{array}$ & $\begin{array}{l}\text { Was allocation } \\
\text { adequately concealed? }\end{array}$ \\
\hline $\begin{array}{l}\text { Blinding of } \\
\text { participants, } \\
\text { personnel and } \\
\text { outcome assessors } \\
\text { Assessments } \\
\text { should be made } \\
\text { for each main } \\
\text { outcome } \\
\text { (or class of } \\
\text { outcomes) }\end{array}$ & $\begin{array}{l}\text { Describe all measures used, if any, to blind study participants and } \\
\text { personnel from knowledge of which intervention a participant received. } \\
\text { Provide any information relating to whether the intended blinding } \\
\text { was effective }\end{array}$ & $\begin{array}{l}\text { Was knowledge of the } \\
\text { allocated intervention } \\
\text { adequately prevented } \\
\text { during the study? }\end{array}$ \\
\hline $\begin{array}{l}\text { Incomplete } \\
\text { outcome data } \\
\text { Assessments } \\
\text { should be made } \\
\text { for each main } \\
\text { outcome } \\
\text { (or class of } \\
\text { outcomes) }\end{array}$ & $\begin{array}{l}\text { Describe the completeness of outcome data for each main outcome, } \\
\text { including attrition and exclusions from the analysis. State whether } \\
\text { attrition and exclusions were reported, the numbers in each } \\
\text { intervention group (compared with total randomised participants), } \\
\text { reasons for attrition/exclusions where reported, and any } \\
\text { re-inclusions in analyses performed by the review authors }\end{array}$ & $\begin{array}{l}\text { Were incomplete } \\
\text { outcome data } \\
\text { adequately } \\
\text { addressed? }\end{array}$ \\
\hline $\begin{array}{l}\text { Selective } \\
\text { outcome } \\
\text { reporting }\end{array}$ & $\begin{array}{l}\text { State how the possibility of selective outcome reporting was examined } \\
\text { by the review authors, and what was found }\end{array}$ & $\begin{array}{l}\text { Are reports of the } \\
\text { study free of } \\
\text { suggestion of selective } \\
\text { outcome reporting? }\end{array}$ \\
\hline $\begin{array}{l}\text { Other sources } \\
\text { of bias }\end{array}$ & $\begin{array}{l}\text { State any important concerns about bias not addressed in the other } \\
\text { domains in the tool } \\
\text { If particular questions/entries were prespecified in the review's } \\
\text { protocol, responses should be provided for each question/entry }\end{array}$ & $\begin{array}{l}\text { Was the study } \\
\text { apparently free of } \\
\text { other problems that } \\
\text { could put it at a high } \\
\text { risk of bias? }\end{array}$ \\
\hline
\end{tabular}

results being entered into the analysis.

- If patient populations, interventions, comparisons or outcomes vary significantly, it may be inappropriate to pool study results.

- Equally, even if studies appear similar, if there is significant heterogeneity in the results, this may also raise the question of whether it is reasonable to carry out a statistic aggregation. Where heterogeneity exists, use of an appropriate pooling method (for example, random-effects pooling, meta-regression analysis) may help mitigate the risk of reaching a biased conclusion.
Finally, the results need to be presented in a meaningful fashion that enables clinical decisions to be taken.

\section{Practical examples of EBM}

EBM is not a purely academic or financial exercise, however - its implementation has major clinical implications.

\section{Single studies: Management of fever in children (evidence level 1+) \\ Fever is common in the under-fives and, although usually benign, may occasionally cause convulsions. This risk, combined with}


the desire to alleviate symptoms in infants, has led to widespread use of paracetamol or ibuprofen as antipyretics. Current NICE guidelines state that either approach is effective. ${ }^{16}$ However, many parents will also use a combination of both agents, in the belief that this will enhance speed of resolution. Is this belief based in reality?

A UK primary care-based study randomised 156 children aged between six months and six years to receive either paracetamol alone, ibuprofen alone or a combination, as treatment for pyrexia $\left(37.8-41.0^{\circ} \mathrm{C}\right)$ in the presence of otitis media managed at home. Treatment was given for the first 24 hours to all patients and for the subsequent 24 hours if symptoms demanded. Randomisation was by automated system and blinding was maintained using a double-dummy approach. ${ }^{17}$

The primary outcome was a comparison of the mean time without fever in the first four hours. Children taking paracetamol alone had significantly less time free of fever than those on combination therapy (116.2 versus 171.1 minutes; $p<0.001)$. There was no significant difference between those taking ibuprofen alone and those on combination therapy (156.0 versus 171.1 minutes; $p=0.2$ ). ${ }^{17}$

Secondary outcomes included 24- and 48hour assessments, as well as mean temperature, time to first temperature relief and a range of patient-related outcomes. These all showed the same qualitative trend, with combination therapy being significantly better than paracetamol alone, but generally showing non-significant benefits versus ibuprofen alone. Ibuprofen alone was also significantly better than paracetamol alone for both the primary outcome and most secondary outcomes. ${ }^{17}$

This study gives practical information for primary care - suggesting that combination therapy offers advantages over paracetamol alone, although probably not over ibuprofen.

\section{Systematic reviews: Heparin in venous thromboembolic disease (evidence level 1++)}

Deep vein thrombosis (DVT) and pulmonary embolism (PE) are major causes of death and disability. Overall, clinically recognised DVT and/or PE occurs in about 0.5 persons per
1,000 each year, although rates in the elderly are approximately four times this figure. ${ }^{18}$ Exposure to specific risk factors such as immobilisation, lower limb injury, surgery and acute severe infection results in a dramatic increase in risk. ${ }^{19}$

The use of heparin underlies both prevention and treatment of DVT/PE, with treatment protocols having been examined in a bewilderingly large range of RCTs. However, study quality is variable and makes the identification of the optimum treatment something of a challenge. This is an ideal field for the use of systematic review and metaanalysis, provided that these have been carried out to high standards - the ideal source for this level of data is the Cochrane Collaboration, which applies a consistent valid protocol to all the reviews published under its auspices.

There are many Cochrane reviews in the field of thromboembolic disease, each addressing a single explicit clinical question. Areas addressed include:

- What is the best strategy for preventing DVT in high-risk situations?

- What is the best treatment for established thromboembolic disease?

- Is treatment best given in a hospital or home environment?

All the reviews give details on protocol, search strategy, included and excluded studies and quality appraisal narratives for all studies. Comprehensive results are given for both individual studies and the pooled results of the meta-analyses, to inform the decisionmaking process (Figure 1). ${ }^{20}$

By working through the various reviews, we can ascertain that:

- Prophylactic treatment with heparin reduces occurrence of DVT in high-risk patients ${ }^{20-23}$

- Use of low molecular weight heparin (LMWH) in patients with established thromboembolic disease is associated with fewer thrombotic complications, lower mortality and a lower risk of haemorrhage ${ }^{24}$

- Use of LMWH at home is associated with better outcomes and fewer serious adverse effects than either unfractionated heparin or LMWH used in hospital ${ }^{25}$

- Twice-daily dosage is preferable to oncedaily. ${ }^{26}$ 


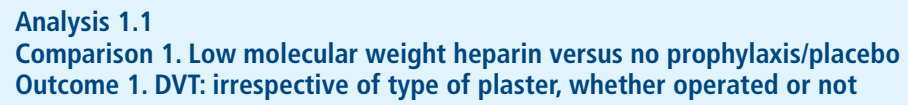

Comparison 1: Low molecular weight heparin versus no prophylaxis/placebo

Outcome 1: DVT: irrespective of type of plaster, whether operated or not

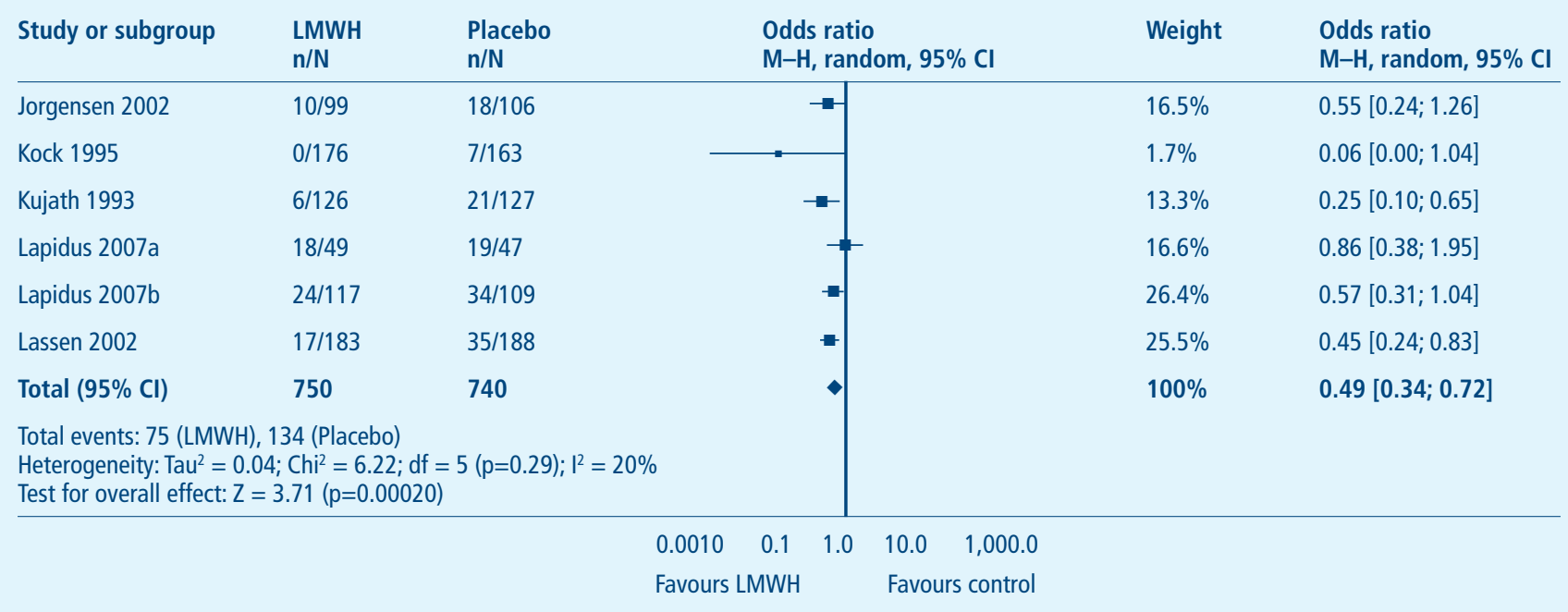

Cl: confidence interval; DVT: deep vein thrombosis; LMWH: low molecular weight heparin; M-H: Mantel-Haenszel test

Figure 1. Typical results of a Cochrane review ${ }^{20}$

This approach exemplifies how complex questions that are not amenable to singlestudy answers can be addressed using welldesigned systematic reviews utilising a standardised methodology.

\section{Non-randomised studies: Influenza vaccination in over-65s (evidence level 2++)}

Current UK guidance mandates routine influenza vaccination for all patients aged 65 and over, in addition to those younger patients with diabetes, immunosuppression or various forms of chronic pulmonary, cardiovascular, renal and liver disease. ${ }^{27}$ Although the majority of those aged over 65 are vaccinated (74.1\% in England in 2008) achievement of adequate vaccination in younger at-risk patients is substantially lower $-47.1 \%$ in $2008 .^{28}$

The evidence that improving vaccine coverage is worthwhile is mixed. In the Netherlands, where an intensive national strategy achieved vaccination rates of $80 \%$ in the 1990s, a 20\% reduction in influenzarelated mortality in the elderly was seen..$^{29}$ In the USA, however, no such benefit has been detected in retrospective studies. ${ }^{30}$

The problem when assessing the benefit of any vaccination strategy is that RCTs are difficult to carry out in this context. ${ }^{31}$

- Mortality is rare, even among high-risk groups, so very large sample sizes are required.

- Demonstration of benefit depends on the circulating virus matching that contained in the vaccination, a requirement that cannot be relied on in advance.

- The administration of a placebo to at-risk patients may well be considered unethical. For this reason, we must depend on the results of case-control studies or cohort analyses, study types that are inherently more prone to bias because of the presence of confounding clinical features. A systematic review of studies assessing vaccine effectiveness showed that the presence of confounders resulted in anything between a $220 \%$ underestimate to a $21 \%$ overestimate of influenza vaccine effectiveness. ${ }^{32}$ Any assessment of vaccine benefit must, therefore, take very careful account of these factors. 
A retrospective cohort study from the USA reviewed the impact of influenza vaccination in those aged over 65 in five US states. ${ }^{33} \mathrm{~A}$ total of 713,872 patient-years were available for analysis, with an overall vaccination rate of around $58 \%$. Common confounders such as age, gender, co-existing medical conditions and prior use of healthcare facilities were taken into account when calculating the results: vaccination appeared to reduce the risk of hospitalisation for influenza or pneumonia by $27 \%$ ( $95 \%$ confidence interval [CI]: 23-32\%) and the seasonal all-cause mortality rate by $48 \%$ (95\% CI: $45-50 \%)$. A particular strength of this analysis is that the authors then went on to explore what the impact on these results would have been if there had been an unsuspected confounder (Table 2). ${ }^{33}$ The results show that even if a powerful confounder had been present, resulting in a threefold increase in risk and present in $60 \%$ of patients, substantial mortality benefit would remain. ${ }^{33}$

This study exemplifies how, in the absence of RCTs, careful use and interpretation of non-randomised studies can nonetheless yield results of clinical significance.

\section{Conclusion}

In the 15 years since EBM first emerged as a coherent approach to assessing treatment options, we have seen its adoption, alongside health economics, as the gold standard tool for commissioning and provision of health services, both in the UK and around the world. It is being applied not only to pharmaceutical treatments but also increasingly to surgical interventions, diagnostic tests and medical devices. Additionally, improved access to resources and integration with medical IT systems means that clinicians are now, more than ever, in a position to implement evidence at the point of contact with individual patients, ensuring that evidence is translated into practice.

Perhaps the area where work remains to be done is in the effective communication of the EBM message to patients. There is still a

Table 2. Example of how confounder effect can be factored into the results of nonrandomised studies ${ }^{33}$

\begin{tabular}{|c|c|c|c|c|c|}
\hline \multirow{2}{*}{$\begin{array}{l}\text { Increase in } \\
\text { the risk of } \\
\text { outcome on } \\
\text { account of } \\
\text { the confounder }\end{array}$} & \multirow[t]{2}{*}{$\begin{array}{l}\text { Prevalence of } \\
\text { confounder (\%) }\end{array}$} & \multicolumn{2}{|c|}{$\begin{array}{l}\text { Hospitalisation for } \\
\text { pneumonia or influenza }\end{array}$} & \multicolumn{2}{|c|}{ Death } \\
\hline & & $\begin{array}{l}\text { Vaccine } \\
\text { effectiveness } \\
(\%)\end{array}$ & $\begin{array}{l}\text { Adjusted } \\
\text { odds ratio } \\
\text { (95\% Cl) }\end{array}$ & $\begin{array}{l}\text { Vaccine } \\
\text { effectiveness } \\
(\%)\end{array}$ & $\begin{array}{l}\text { Adjusted odds } \\
\text { ratio } \\
(95 \% \mathrm{Cl})\end{array}$ \\
\hline- & 0 & 27 & $\begin{array}{l}0.73 \\
(0.68,0.77)\end{array}$ & 48 & $\begin{array}{l}0.52 \\
(0.50,0.55)\end{array}$ \\
\hline Doubled & 20 & 20 & $\begin{array}{l}0.80 \\
(0.75,0.85)\end{array}$ & 43 & $\begin{array}{l}0.57 \\
(0.55,0.60)\end{array}$ \\
\hline Doubled & 40 & 15 & $\begin{array}{l}0.85 \\
(0.80,0.90)\end{array}$ & 40 & $\begin{array}{l}0.60 \\
(0.58,0.63)\end{array}$ \\
\hline Doubled & 60 & 14 & $\begin{array}{l}0.86 \\
(0.81,0.92)\end{array}$ & 39 & $\begin{array}{l}0.61 \\
(0.59,0.65)\end{array}$ \\
\hline Tripled & 20 & 14 & $\begin{array}{l}0.86 \\
(0.81,0.92)\end{array}$ & 38 & $\begin{array}{l}0.62 \\
(0.59,0.64)\end{array}$ \\
\hline Tripled & 40 & 9 & $\begin{array}{l}0.91 \\
(0.86,0.97)\end{array}$ & 35 & $\begin{array}{l}0.65 \\
(0.63,0.69)\end{array}$ \\
\hline Tripled & 60 & 7 & $\begin{array}{l}0.93 \\
(0.87,0.99)\end{array}$ & 33 & $\begin{array}{l}0.67 \\
(0.64,0.70)\end{array}$ \\
\hline
\end{tabular}


perception - often fuelled by an ill-informed media $^{34}$ - that decisions to restrict NHS treatments are always purely financial in nature. While this may well be the case in some circumstances, the removal of ineffective or potentially harmful treatments from the NHS should serve to enhance the quality of healthcare: communicating this perspective will represent the next challenge for EBM.

\section{References}

1. Department of Health. The National Health Service: A Service with Ambitions. www.archive.official-

documents.co.uk/document/doh/ambition/ambition.htm (last accessed 27 April 2009)

2. Rosenberg W, Donald A. Evidence based medicine: an approach to clinical problem-solving. BMJ 1995; 310: 1122-1126.

3. Medical Research Council. Streptomycin treatment of pulmonary tuberculosis. BMJ 1948; 2: 769-782. 4. Medical Research Council. Clinical trial of patulin in the common cold. Lancet 1944; ii: 373-375.

5. Cochrane A. Effectiveness and Efficiency: Random

Reflections on Health Services. London: Royal Society of

Medicine Press, 1999

6. Evidence-Based Medicine Working Group. Evidence-

based medicine. A new approach to teaching the practice of medicine. JAMA 1992; 268: 2420-2425.

7. Eddy DM. Practice policies: where do they come from? JAMA 1990; 263: 1265, 1269, 1272 passim. 8. Sackett DL, Rosenberg WM, Gray JA, Haynes RB, Richardson WS. Evidence based medicine: what it is and what it isn't. BMI 1996; 312: 71-72.

9. Taylor R, Taylor R. What is health technology assessment? London: Hayward Medical Communications, 2009.

10. Scottish Intercollegiate Guidelines Network. SIGN 50:

A guideline developer's handbook.

www.sign.ac.uk/pdf/sign50.pdf (last accessed 12 November 2008)

11. Hemmingway P, Brereton N. What is a systematic review? London: Hayward Medical Communications, 2009.

12. Higgins JPT, Green S. Cochrane Collaboration. Cochrane Handbook for Systematic Reviews of Interventions, Version 5.0.1 [updated September 2008]. Chapter 8: Assessing risk of bias in included studies. www.cochranehandbook.org (last accessed 12 November 2008) 13. Crombie IK, Davies HTO. What is meta-analysis? London: Hayward Medical Communications, 2009. 14. Akobeng AK. Understanding systematic reviews and meta-analysis. Arch Dis Child 2005; 90: 845-848. 15. Egger M, Smith GD, Phillips AN. Meta-analysis: principles and procedures. BMJ 1997; 315: 1533-1537.

16. National Institute for Health and Clinical Excellence. Clinical Guideline 47: Feverish illness in children: Assessment and initial management in children younger than 5 years. www.nice.org.uk/nicemedia/pdf/CG47NICEGuideline.pd f (last accessed 12 November 2008)

17. Hay AD, Costelloe C, Redmond NM et al. Paracetamol plus ibuprofen for the treatment of fever in children
(PITCH): randomised controlled trial. BMJ 2008; 337: a1302.

18. Fowkes FJ, Price JF, Fowkes FG. Incidence of diagnosed deep vein thrombosis in the general population: systematic review. Eur J Vasc Endovasc Surg 2003; 25: 1-5.

19. Kyrle PA, Eichinger S. Deep vein thrombosis. Lancet 2005; 365: 1163-1174.

20. Testroote M, Stigter W, de Visser DC, Janzing H. Low molecular weight heparin for prevention of venous thromboembolism in patients with lower-leg immobilization. Cochrane Database Syst Rev 2008; CD006681.

21. Handoll HH, Farrar MJ, McBirnie J et al. Heparin, low molecular weight heparin and physical methods for preventing deep vein thrombosis and pulmonary embolism following surgery for hip fractures. Cochrane Database Syst Rev 2002; CD000305.

22. Ramos J, Perrotta C, Badariotti G, Berenstein G. Interventions for preventing venous thromboembolism in adults undergoing knee arthroscopy. Cochrane Database Syst Rev 2008; CD005259.

23. Wille-Jorgensen P, Rasmussen MS, Andersen BR, Borly L. Heparins and mechanical methods for thromboprophylaxis in colorectal surgery. Cochrane Database Syst Rev 2003; CD001217.

24. van Dongen CJ, van den Belt AG, Prins MH, Lensing AW. Fixed dose subcutaneous low molecular weight heparins versus adjusted dose unfractionated heparin for venous thromboembolism. Cochrane Database Syst Rev 2004; CD001100.

25. Othieno R, Abu Affan M, Okpo E. Home versus inpatient treatment for deep vein thrombosis. Cochrane Database Syst Rev 2007; CD003076.

26. van Dongen CJ, MacGillavry MR, Prins MH. Once versus twice daily LMWH for the initial treatment of venous thromboembolism. Cochrane Database Syst Rev 2005; CD003074.

27. Department of Health. The Influenza Immunisation Programme 2008/09.

www.dh.gov.uk/en/Publicationsandstatistics/Lettersandci rculars/Professionalletters/Chiefmedicalofficerletters/DH 083812?IdcService=GET_FILE\&dID=169312 \& Rendition= Web (last accessed 14 January 2009)

28. Department of Health. NHS Immunisation Information: Vaccine uptake in England 2008/09. www.immunisation.nhs.uk/Vaccines/Flu/Resources/vacci ne uptake_2008_2009 (last accessed 13 January 2009) 29. Jansen AG, Sanders EA, Nichol KL et al. Decline in influenza-associated mortality among Dutch elderly following the introduction of a nationwide vaccination program. Vaccine 2008; 26: 5567-5574.

30. Simonsen L, Taylor RJ, Viboud C, Miller MA, Jackson LA. Mortality benefits of influenza vaccination in elderly people: an ongoing controversy. Lancet Infect Dis 2007; 7: 658-666.

31. Hak E. Collaborative efforts are needed to improve use of influenza immunisation in Europe. Euro Surveill 2008; 13: 19011.

32. Valenciano M, Ciancio B, Moren A et al. First steps in the design of a system to monitor vaccine effectiveness during seasonal and pandemic influenza in EU/EEA Member States. Euro Surveill 2008; 13: 19015.

33. Nichol KL, Nordin JD, Nelson DB, Mullooly JP, Hak E. Effectiveness of influenza vaccine in the communitydwelling elderly. N Engl J Med 2007; 357: 1373-1381. 34. www.dailymail.co.uk/health/article-1054049/Drugwatchdog-NICE-spends-spin-tests-new-treatments.html (last accessed 13 January 2009) 


\section{What is...? series}

\section{What is}

evidence-based medicine?

First edition published 2001 Authors: Jonathan Belsey and Tony Snell

This publication, along with the others in the series, is available on the internet at www.whatisseries.co.uk The data, opinions and statements appearing in the article(s) herein are those of the contributor(s) concerned. Accordingly, the sponsor and publisher, and their respective employees, officers and agents, accept no liability for the consequences of any such inaccurate or misleading data, opinion or statement.

Published by Hayward Medical Communications, a division of Hayward Group Ltd.

Copyright (C) 2009 Hayward Group Ltd.

All rights reserved. 